\title{
Questão agrária no Brasil: a batalha entre o agronegócio e a agroecologia
}

\section{Agrarian issue in Brazil: the battle between agribusiness and agroecology}

\author{
Maristela Dalmoro $^{a}$
}

\begin{abstract}
Resumen
Esse trabalho tem como objetivo problematizar a realidade agrária brasileira e sua manifestação contemporânea materializada no que se convenciona chamar de agronegócio. $\mathrm{O}$ modelo produtivo sustentado no agronegócio é tributário da política adotada pelos governos militares a partir de meados da década de 1960, mas ganha maturidade nos anos 90 com a hegemonia do neoliberalismo e tem avançado significativamente na destruição dos recursos naturais, tais como a terra, água, florestas etc. Em contraponto a este modelo vem se constituindo um novo modelo produtivo que aponta caminhos para preservação da natureza e de todas as formas de vida. A agroecologia se torna a estratégia de resistência de várias organizações e movimentos sociais e se volta à produção de produtos saudáveis, garantindo, com isso, o princípio da soberania alimentar. O MST, que na sua origem adota a matriz produtiva advinda da Revolução Verde, a partir dos anos 2000 se torna uma das maiores referências na defesa da agroecologia considerando-a uma estratégia de resistência contra o agronegócio e de defesa da Soberania Alimentar.
\end{abstract}

Palabras clave: questão agrária, Brasil, agronegócio, agroecologia. a Universidade Federal do Rio de Janeiro (ESS-UFRJ), Brasil.

Correspondencia a: dalmororj@uol.com.br

Recibido:

31 octubre 2018

Aceptado:

13 diciembre 2018

Artículo publicado en acceso abierto bajo la Licencia Creative Commons.

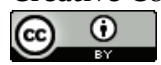

Cita:

Dalmoro, M. (2018). Questão agrária no Brasil: a batalha entre o agronegócio e a agroecologia. Rera Yvoty: reflexiones sobre la cuestión social, 3, 94-106. 
which in its origin adopts the productive matrix arising from the Green Revolution, from the 2000 s has become one of the major references in the defense of agroecology considering it a strategy of resistance against agribusiness and defense of Food Sovereignty.

Keywords: agrarian question, Brazil, agribusiness, agroecology.

\section{Introducción}

As últimas décadas, no Brasil, foram marcadas por importantes mudanças em todos os âmbitos da sociedade o que, salvo alguns avanços, consolidam profundos retrocessos que se manifestam no aprofundamento da desigualdade social, da violência, do autoritarismo, etc. Analisando a partir perspectiva que orienta o Serviço Social, que tem a questão social como referência, ver-se-á dados alarmantes, demonstrados nas suas mais diversas expressões. Para compreender esse cenário é necessário lançar o olhar para mais longe e decifrar os fios que tecem esse processo. Isso nos remete a compreender a própria formação social do Brasil e seus traços escravistas e concentracionistas, mas é indubitável que o esforço empreendido pelos setores dominantes, nos últimos anos, tendo como fim único garantir a recomposição da ordem burguesa em meio à crise estrutural do capital, é fundante da atual estrutura social e do campo brasileiro.

Aproduçãoagrícola semprefoi central no processo de acumulação capitalista enquanto produtora de mercadorias para o mercado externo, mas para o que o debate deste artigo, é importante apontar o cenário contemporâneo e o lugar da agricultura na produção de commodities para serem negociadas no mercado mundial em um claro aceno ao capital especulativo em detrimento da produção para abastecer o mercado de alimentos. Essa política capitaneada pelo Estado brasileiro com clara orientação neoliberal, se dá através de fortes investimentos, através de incentivos, financiamentos, subsídios, e traz a marca de uma nação que se forma historicamente sob o jugo do monopólio da terra e do capital e se atualiza dando corpo ao que hoje se denomina de agronegócio.
Este artigo se propõe a problematizar esta realidade, concentrando os esforços nas manifestações contemporâneas. Para explicitar isso, é importante ter conta as determinações históricas constituídas desde o processo de colonização do Brasil e seu papel no processo de acumulação primitiva do capital. Os desdobramentos posteriores que se voltam a atender a demanda do mercado urbano-industrial e o mercado externo de produtos primários, consolidando o modelo fundado no latifúndio ea marginalização dos segmentos de trabalhadores e da produção camponesa. A maior expressão deste projeto pode ser debitada ao que passou a ser denominada de Modernização Conservadora consolidada a partir dos anos 1960, momento de aprofundamento da industrialização e da dependência externa modelo claramente inserido no modelo da Revolução Verde. A profunda modernização da agricultura que se consolida a partir desta década, altera radicalmente as relações de produção no campo brasileiro, deixa intactas as relações de propriedade a qual ganha novos contornos a partir dos anos de 1990, momento de hegemonia do agronegócio.

Por outro lado, e contraditoriamente, vai se forjando a resistência de um amplo setor de trabalhadores do campo os quais passaram a ser reconhecidos como camponeses. São estes que se tornam os grandes protagonistas das lutas sociais no campo empreendidas, principalmente a partir de finais dos anos 70 e início da década de 80 momento em que ganha relevância e status a luta pela terra e pela reforma agrária. Foi essa luta que se fortalece nos anos subsequentes que cria as condições para a constituição de uma nova matriz produtiva para o campo fundamentado 
na agroecologia. Para os limites deste artigo, pretende-se tratar desse movimento que hoje pode ser considerado o mais importante do Brasil e da América Latina e que se opõe radicalmente ao agronegócio. Será dado ênfase a trajetória do MST e sua opção ainda que tardia pela agroecologia na medida que reconhece os efeitos predatórios e a insustentabilidade social, econômica e ambiental do agronegócio. A incorporação da matriz produtiva advinda da agroecologia se torna a estratégia de superação dos entraves impostos pelo modelo hegemônico e representa defesa dos princípios da Soberania Alimentar.

\section{A ocupação do espaço agrário e o desenvolvimento do capitalismo no campo brasileiro}

Para início do debate é necessário ressaltara relaçãoque existe entreo histórico processo de ocupação do espaço agrário no Brasil com o fenômeno chamado hoje de agronegócio. Fernandes, Welch, Gonçalves (2010) apontam que essa denominação ganha espaço a partir dos anos go e traz uma carga ideológica na medida em que busca desligar a grande propriedade ao latifúndio que se sustenta na exploração, no trabalho escravo, na profunda concentração da terra e nas relações de atraso, tanto político como econômico. Enfatiza esse autor, que não há como desconectar o que hoje se conhece como agronegócio de sua origem colonial sustentado no sistema de plantation e na grande propriedade cuja produção destinase à exportação.

Nas palavras de Caio Prado Junior (1961), a colonização do Brasil se constituiu no que viria a ser a grande propriedade voltada à monocultura e utilizando trabalho organizada no que ele chama de grande empresa comercial que no início se destinou a explorar recursos naturais e, mais tarde passou a produzir produtos agrícolas ao comércio europeu.

Essa é a marca da colonização do Brasil impôs as massas trabalhadoras, uma condição subalterna social e economicamente. A Lei de Terras de 1850, regulamenta a propriedade privada da terra tornando-a mercadoria restringindo ainda mais o seu acesso pelos diversos segmentos de trabalhadores e legitimando uma política agrária profundamente excludente e com estrutura fortemente desigual. A revolução burguesa no Brasil, nas palavras Florestan Fernandes (1987), chamada por ele de contrarrevolução preventiva, afirma que a burguesia que se constitui no Brasil não se interessou por uma revolução nacional e, portanto, não rompeu com a dependência imperialista e nunca assumiu a bandeira republicana de uma sociedade liberal e democrática. $\mathrm{O}$ resultado disso foi a passagem de uma economia agroexportadora para uma urbana industrial processada a partir da Revolução de 1930, sem rupturas. Ao contrário, oligarquias rurais continuam como os donos das terras produzindo para a exportação e, embora a hegemonia política passa para a burguesia urbanoindustrial, as alianças firmadas entre esses dois setores garantem a reprodução dos interesses oligárquicos e a primazia da grande propriedade latifundiária.

Essa origem oligárquica e conservadora da agricultura brasileira vai assumindo novos contornos no decorrer do séculoXXe, principalmente no períodoapós Segunda Guerra Mundial, quando ocorre um amplo processo de modernização da agricultura sob a égide da Revolução Verde. A hegemonia deste projeto que ocorreu após o golpe civil-militar em 1964, se deu através da associação entre a indústria e o setor agrícola, com apoio do Estado, provocando profundas alterações nas relações de trabalho sem alterar as relações de propriedade.

Aprofunda-se, com isso, a concentração fundiária e abre as porteiras para as grandes corporações transnacionais que, segundo Golfarb (2012), tornam-se as propagadoras de novos pacotes tecnológicos que demandam um alto investimento de capital por hectare, com intenso uso de insumos externos e baixo uso de mão de 
obra. A intensa repressão exercida sobre os povos do campo garantiu o controle das forças de resistência que vinham se forjando nos anos anteriores só sendo retomada após as primeiras manifestações de crise e esgotamento deste modelo em meados dos anos 1970, dada a crise estrutural do capital, a qual deixa incerto os rumos da política agrária no Brasil.

Entretanto, essa crise que se estende na década de 1980, e o intenso processo de organização e luta pela terra que se gesta nesse período, a qual dará origem ao Movimento dos Trabalhadores Sem Terra (MST), não possibilitou a alteração da estrutura agrária brasileira. Ao contrário, os anos subsequentes, principalmente a partir da década de 1990, esse modelo se amplifica e passa a ser denominado de agronegócio, uma denominação mais palatável à sociedade tentando demarcar uma ruptura com a imagem do Brasil agrário como atrasado e desigual. O agronegócio se torna a expressão do moderno e, em função de um profundo trabalho ideológico por parte das entidades patronais, pela mídia e pelo próprio Estado, ele se apresenta como o responsável pela Segurança Alimentar e preocupada em diminuir a miséria e proteger o meio ambiente. $O$ certo é que a partir desta década o agronegócio se torna hegemônico e, em função de um mercado externo favorável o que ampliou consideravelmente as exportações de commodities agrícolas e minerais. $\mathrm{O}$ Estado passa a lhe dar especial atenção através da concessão vastos recursos públicos, via financiamentos e subsídios.

\section{O agronegócio e suas expressões contemporâneas: os anos 2000 em questão}

O início dos anos 2000 no Brasil estão marcados por um forte otimismo, resultado da chegado ao poder dos representantes do Partido dos Trabalhadores, um histórico defensor dos interesses dos trabalhadores e, no campo, da reforma agrária. Entretanto, a esperança sofreu duros golpes no decorrer dos treze anos dos governos petistas e se deu pela relação bastante amistosa entre esses governos eos representantes doagronegócio o que ampliou significativamente a produção e exportação de commodities. Os dados apresentados por Nakatani, Faleiros e Vargas (2012), são ilustrativos na medida em que apontam um crescimento de $37 \%$ em 2000 para $51 \%$, em 2010 , do total das exportações de commodities.

Ganham força os argumentos dos representantes do agronegócio que defendem o compromisso deste setor com o desenvolvimento econômico "sustentável" servindo como justificativa ao Estado que passa a apoia-lo através de legislações, jurisprudências, normas e recursos bilionários [..], com muita frequência, em prejuízo de direitos difusos, de minorias, e de demandas democráticas e garantias trabalhistas" (Teixeira, 2013). Fica obscurecido, no entanto, que:

(...) as virtudes econômicas do agronegócio, fruto dessa sustentação do Estado e da sociedade, estão absolutamente voltadas para o lucro dos capitais correspondentes, ignorando interesses nacionais estratégicos. Cada vez mais a pauta de produtos do agronegócio tem ficado restrita a um pequeno grupo de produtos, fundamentalmente ditados pelo mercado externo. Em contrapartida, vê-se configurada a ameaça ao abastecimento interno dos alimentos que integram a dieta básica da população. (p. 26)

Importa ressaltar, também, que ao privilegiar um modelo agrícola sustentado no agronegócio o governo apoia também, a adoção de um pacote tecnológico que extremamente nocivo ao meio ambiente e a saúde e que se baseia em um consumo crescente de recursos naturais não produzidos pelo trabalho humano, tais como os solos, a água, a biodiversidade, as florestas nativas, etc. Esse modelo cuja racionalidade se assenta no máximo aproveitamento dos bens naturais, destrói 
a vida em nome do combate às pragas e do controle de doenças na agricultura.

De acordo com Bombardi (2012), o Brasil, alcançou em 2009 o primeiro lugar no ranking mundial de consumo de agrotóxicos, e isso não o coloca como o maior produtor agrícola mundial. Quem ganha com isso são as indústrias produtoras dos venenos agrícolas, que nesse período tiveram uma receita líquida de cerca de 15 bilhões de reais. A situação é mais grave ainda, quando se constata, segundo a autora, que $92 \%$ dessas receitas são controlados por empresas de capital estrangeiro, mais especificamente seis grandes grupos transnacionais que são: Syngenta (Suiça), Dupont (Estados Unidos), Dow Chemical (Estados Unidos), Bayer (Alemanha), Novartis (Suiça), Basf (Alemanha) e Milenia (Holanda/Israel) ${ }^{1}$.

Além dos prejuízos que esse uso indiscriminado dos agrotóxicos provoca à agricultura, as pesquisas vêm apontando um problema grave e ainda pouco denunciado que é o problema de saúde pública. Bombardi (2012), com base, nos dados do SINITOX (Sistema Nacional de Informações Tóxico Farmacológicas Ministério da Saúde/FIOCRUZ), afirma que, de 1999 a 2009 foram notificadas cerca de 62 mil intoxicações por agrotóxicos de uso agrícola. Isto significa que tivemos por volta de 5.600 intoxicações por ano no país, o que equivale a uma média de 15,5 intoxicações diárias, ou uma a cada 90 minutos ${ }^{2}$.

Essa subordinação da agricultura brasileira aos interesses dos grandes grupos

\footnotetext{
1 Segundo Bombardi (2012, p. 1) Nestes dados não estão incluídos as informações da receita da Monsanto fabricante do glifosato round up, herbicida vendido em larga escala no Brasil e popularmente conhecido como mata mato, o que nos permite afirmar que este número é sem dúvida muito maior.

$2 \mathrm{O}$ resultado do uso indiscriminado destes produtos está sendo denunciado de diversas formas. Vale mencionar a Campanha Contra os Agrotóxicos e Pela Vida que tem o objetivo de sensibilizar a população brasileira para os riscos que os agrotóxicos. Segundo dados divulgados por essa Campanha, cada brasileiro consome em torno de 5,2 litros de agrotóxico por ano.
}

transnacionais que atinge, também a pequena e média agricultura, incentivada a utilizar as mesmas práticas de cultivo com uso intensivo de agrotóxicos, fica ainda mais intensa com o advento dos transgênicos. A primeira Medida Provisória que libera o uso desse tipo de sementes aconteceu em março de 2003, no início do governo Lula. Esta Medida autoriza o plantio da semente de soja RR3. Posteriormente, com Lei de Biossegurança (Lei no 11.105, de 2005) as sementes transgênicas foram completamente na agricultura mesmo com as advertências feitas por diversos pesquisadores e entidades quanto ao desconhecimento acerca dos efeitos sobre seu uso.

De acordo com Nodari e Guerra (2003) A transgenia veio para aprofundar ainda mais a dependência econômica e destruir os conhecimentos tradicionais acerca da produção das sementes. Nesse tipo de tecnologia são inseridos genes que dependem de um produto químico para que voltem a ter funcionalidade. Nessas situações, os produtores além de serem obrigados a pagar royalties a cada compra de semente, o que vai aumentar os custos da produção, as empresas cobram taxas tecnológicas ainda mais abusivas que incidem sobre o valor do produto final comercializado (Teixeira, 2013).

O mais graveainda, équeessecontrole exercido pelas grandes empresas sobre a produção de sementes geneticamente modificadas se aprofunda ainda mais, pois estas dominam, também, outros setores que são interligados tecnicamente com o das sementes, como os de fertilizantes agroquímicos, os farmacêuticos e produtos veterinários.

O domínio por um pequeno grupo de empresas capitalistas multinacionais sobre a produção de sementes transgênicas e dos demais insumos necessários para produzi-

\footnotetext{
3 A soja Roundup Ready, conhecida como RR, possui características que a torna tolerante ao herbicida à base de glifosato usado para dissecação pré e pós plantio.
} 
las determinará diretamente o controle sobre os alimentos que serão oferecidos para o consumo humano e animal em todo o mundo. Isso poderá significar, mais do que já está ocorrendo, não apenas uma padronização da dieta alimentar mundial como o domínio das empresas privadas de alimentos sobre o paladar das pessoas, reforçando a imposição subliminar pela dieta oferecida. Essa nova forma de tirania é consequência da redução crescente da diversidade das sementes, assim como da sua artificialização pela produção de sementes transgênicas (Carvalho, 2005, p. 2).

Se essa política foi hegemônica no decorrer dos treze anos dos governos petistas, o quadro se aprofunda ainda mais a partir de 2016 com o golpe jurídicoparlamentar-midiático. $\mathrm{O}$ então vicepresidente da República Michel Temer assumiu à Presidência com o discurso de que novas e radicais medidas deveriam ser tomadas para conter a forte crise política e econômica que assolava o país. No entanto, um olhar mais atento leva ao deslindamento da política que deveria ser adotada por esse governo num claro avanço de políticas ultra neoliberais que deveriam ser implementadas através de ajustes estruturais. A base deste novo ciclo deveria se assentar no "equilíbrio fiscal", constituído através do corte de gastos públicos diminuindooendividamentoeaumentando o superávit primário. Para isso o governo lança mão de uma série de contrarreformas que causa o desmantelamento das políticas sociais. A direção não é diferente quando se trata das políticas agrárias e agrícolas voltados aos trabalhadores do campo, o que vem significando uma derrota da reforma agrária, da agricultura camponesa e dos movimentos e organizações sociais dos trabalhadores.

É notório a adesão de setores do agronegócio a esse governo que tem início com o protagonismo tanto da bancada ruralista no Congresso como das entidades patronais e empresários do setor, ao golpe parlamentar-judiciário-midiático de 2016. A primeira medida tomada em benefício desse setor foi a nomeação como ministro da agricultura um dos maiores sojeiros do Brasil, eatuante na luta contra a demarcação das terras indígenas no estado do Mato Grosso, Blairo Maggi. Ao mesmo tempo, extingue o Ministério do Desenvolvimento Agrário (MDA) incorporando-o, em um primeiro momento, ao Ministério do Desenvolvimento Social (MDS) e logo em seguida, através do Decreto 8780, incorpora à Casa Civil, rebaixando-o a uma Secretária. Várias medidas foram sendo tomadas nos dois anos deste governo, e que foram somente o início da clara tendência de desmantelamento das políticas e programas voltados a atender os interesses dos povos do campo que se aprofunda consideravelmente com a posse do governo de ultradireita e com traços fascistas. Fica evidente desde sua campanha e nesses aproximadamente noves meses de mandato, a intensão de criminalizar os movimentos sociais, de flexibilizar a legislação ambiental, e de reduzir drasticamente as verbas às políticas e programas vinculados aos interesses dos trabalhadores do campo. A opção deste governo pelo agronegócio fica explicita quando se analisa a aprovação de novos registros de agrotóxicos. Até outubro de 2019, já haviam sido feitos em torno de 400 novos registros, o representa um profundo retrocesso e agudiza ainda mais os problemas relativos ao uso indiscriminado destas substancias, tanto para a saúde humana e animal quanto para a natureza.

O que se pode imputar até o momento é que o Estado sob o comando deste governo de ultradireita, o qual conta com o apoio de setores importantes da burguesia nacional e internacional, ampliará ainda mais o domínio do agronegócio, no Brasil, desdobrando-se disso sérias consequências ao campo social e ambiental que se manifestarão no aprofundamento da concentração da terra, no aumento da quimificação e do uso de transgênicos, na precarização ainda maior das relações de trabalho, no aumento da violência contra os trabalhadores e movimentos sociais. Aponta-se, com isso, o aprofundamento da 
desigualdade social e abrindo-se uma nova fase na luta pela terra, pela reforma agrária e pela soberania alimentar.

\section{O Campesinato e a agroecologia na contracorrente}

Não obstante os rumos das políticas voltadas à agricultura, que como asseveramos acima, sempre atenderam os interesses da propriedade monocultora voltada ao mercado externo, o campesinato se apresenta como um importante protagonista que a princípio era responsável pela produção de alimentos e fornecedor de mão de obra para as grandes fazendas, mas que a partir do último terço do século XX se torna umas das forças conta hegemônicas mais importantes do Brasil.

Sua origem remonta ao período colonial, formado principalmente, por descendentesdeescravoslivres, deindígenas e outros segmentos de trabalhadores pobres. Estes passam a ocupar as margens das grandes propriedades, muitas vezes sob a anuência do proprietário, para atender a demanda de mão de obra sazonal ou, em alguns casos fazendo parte de exércitos privados em ocasiões de disputas de terras ou conflitos socioterritoriais. Sua reprodução no decorrer do processo de ocupação do espaço agrário brasileiro se deu pela sua capacidade de reinventar-se e pelas lutas travadas em diversões momentos e rincões do Brasil.

A resistência dos povos do campo é uma marca importante na história do Brasil e traz a marca da resistência dos indígenas e escravos e, posteriormente os camponeses que de início constitui-se com uma luta assentada no messianismo, mas com o aprofundamento da exploração e expropriação capitalista, ganha novos contornos e assume um viés claramente político e de luta de classes. Vale ressaltar aqui o protagonismo do movimento camponês que se organiza através dos anos 50 e 60 consolidando as Ligas Camponesas ${ }^{4}$,

4 Para uma maior compreensão das Ligas Camponesas ver Morais (1997). o primeiro movimento cuja demanda era a realização da reforma agrária.

O golpe impetrado em 1964, sufoca a organização camponesa e impõem um regime de exceção, punindo as lideranças e camponeses, interditando qualquer manifestação em defesa dos interesses dos trabalhadores e da reforma agrária no Brasil. Foi um período de forte repressão e controle sobre os trabalhadores de modo geral, e foi também uma fase de aprofundamento das desigualdades sociais e, especificamente no campo, momento de acirramento de contradições sociais e de alguns conflitos por terra e por trabalho ${ }^{5}$.

Essas tensões ganham espaço a partir de meados da década de 70, comos primeiros sinais de crise do projeto implementado pelo regime civil-militar tendo à frente setores da Igreja Católica, através da Comissão Pastoral da Terra (CPT), a qual se tornou a força mais importante na luta pela terra e da reforma agrária. Pode-se dizer que o MST é caudatário desta luta capitaneada pela CPT, pois foi esta que possibilitou a reorganização dos camponeses e trabalhadores de modo geral no campo e deu as bases para o início da luta pela reforma agrária. As primeiras manifestações ocorreram no sul do Brasil e através de ocupações de terras e de acampamentos e rapidamente espraia-se para diversas regiões do país possibilitando que em 1984, o Movimento se institucionalize e se torne uma das maiores forças de resistência do Brasil na luta pela reforma agrária o qual se mantem até hoje.

Ressalta-se que esse momento de

\footnotetext{
5 Há vários estudos acerca dos conflitos sociais no decorrer da ditadura civil-militar e estes ocorriam privilegiadamente na região amazônica, pois essa região foi alvo de políticas estatais para incentivar a ampliação da fronteira agrícola. As tensões ocorreram entre os posseiros e indígenas e os grandes proprietários sob a tutela do Estado. Um dos conflitos mais importantes pelo nível de violência e organização foi o movimento guerrilheiro conhecido como Guerrilha do Araguaia que ocorreu no município de Conceição de Araguaia, no estado do Pará. Para um aprofundamento deste ponto ver Ianni, (1978).
} 
efervescência no campo, para além do MST, surgem várias lutas e com as mais diversas demandas o que demonstra o caráter deletério da modernização conservadora e seus efeitos perversos sobre as condições de vida e trabalho dos trabalhadores do campo. Pode-se mencionar aqui a luta dos seringueiros e posseiros na região amazônica, a luta contra a construção de barragens que possibilitou o surgimento do movimento organização chamado Movimento dos Atingidos por Barragens (MAB), que se mantem vivo até os dias de hoje. A luta das mulheres uma força importante nesse momento de luta e que se desdobra, posteriormente no Movimentos das Mulheres Camponesas (MMC), o movimentos quilombola presente na arena política eque juntamente com o Movimento Indígena são uma força importante na luta das comunidades tradicionais, e, por fim, a luta dos pequenos agricultores que dá origem, posteriormente ao Movimento dos Pequenos Agricultores (MPA), hoje um forte aliado na luta do MST e um grande protagonista da defesa da agroecologia e Soberania Alimentar.

Sem desconsiderar a importância destas lutas, nos limites deste artigo concentrarmos nossa análise na luta do MST, por considera-lo o maior representante da luta pela reforma agrária no Brasil e, atualmente tem se apresentado como um dos maiores protagonistas na defesa de um projeto produtivo sustentado na agroecologia e da Soberania Alimentar.

\section{O Debate da agroecologia: da origem a sua consolidação}

Mesmo que esse artigo tenha como objetivo explicitar a agroecologia e a sua incorporação pelo MST, é necessário demonstrar várias ações e avanços que o antecederam e que explicam a vitalidade deste tema. $\mathrm{O}$ movimento agroecológico tem início nos anos de 1970 e, mesmo em pleno auge da Modernização Conservadora se posiciona radicalmente contrário a este modelo produtivo advertindo acerca dos seus efeitos deletérios sobre o meio ambiente. A criação do Projeto de Tecnologias Alternativas (PTA), apoiado pela ONG Federação dos Órgãos para Assistência Social e Econômica (FASE), tornam-seas articuladoras das organizações voltadas ao estimuloà chamada "agricultura alternativa" o que culmina na constituição da AS-PTA (Assessoria e Serviços a Projetos em Agricultura Alternativa).

O debate se amplia a partir da década de 8o, mas os anos 90 intensifica-se muito em função das preocupações com o meio ambiente impulsionada principalmente pela Conferência das Nações Unidas sobre o Meio Ambiente e o Desenvolvimento, a Rio92 que pautou os problemas relacionados a degradação ambiental e a necessidade de reverter os prejuízos já existentes por conta da expansão do modelo industrial e da agricultura convencional. Somado a isso a questão alimentar, um problema bastante discutido internacionalmente, garante a expansão da defesa da agroecologia no Brasil.

A ampliação das organizações voltadas ao assessoramento das famílias e comunidades camponesas e a implementação de vários programas e projetos voltados ao fortalecimento da agroecologia ganha novos contornos a partir da 2003, com o início dos governos petistas. Se por um lado, esses governos impulsionam fortemente o agronegócio, como visto anteriormente, por outro, implementam uma série de políticas para apoiar a agricultura familiar e a promoção da segurança alimentar e nutricional. (Moura, 2017). Pode-se citar como as mais importantes a Política Nacional de Agroecologia e Produção Orgânica (Pnapo), em agosto de 2012, já no governo de Dilma Rousseff, a qual pode ser considerado um marco histórico de grande relevância para o movimento agroecológico brasileiro (Monteiro e Londres, 2017).

Mas o que dará concretude ao tema da agroecologia nesses últimos anos, indubitavelmente é a ampla 
organização da sociedade civil que se efetiva, principalmente na constituição da Articulação Nacional de Agroecologia (ANA). É inegável a importância desta rede ne medida em que se apresenta como um espaço de fortalecimento, articulação e difusão das questões relativas à agroecologia e contribui para estabelecer os elos entre as várias organizações vinculadas à luta e defesa desta proposta. Ademais, saem deste espaço outras iniciativas que dão mais força à luta pela agroecologia e podemos mencionar como uma das mais importantes a realização dos Congressos Brasileiros de Agroecologia (CBA), que em 2017 realizou a sua decima edição, em parceria com o Congresso Latinoamericano de Agroecologia organizado pela Sociedade Cientifica Latino-americana de Agroecologia (SOCLA). Surge dessa rede também, a Associação Brasileira de Agroecologia (ABA), que assume caráter técnico-científico e colabora no âmbito da pesquisa cientifica acerca da agroecologia e responsável atualmente pela realização do CBA.

Especificamente o MST, sobre o qual nos deteremos adiante, sua presença na articulação e organização política de defesa da agroecologia é de fundamental importância. A própria consolidação da ANA e as demais ações apontadas acima contam com uma ampla participação e protagonismo deste Movimento. Por isso entende-se que é importante apontar quais os caminhos trilhados por ele para chegar ao ponto de se tornar uma das maiores forças na defesa da agroecologia no Brasil.

\section{O MST - luta pela terra e pela agroecologia}

Para decifrar a trajetória deste movimento e seu protagonismo na luta pela terra no Brasil e pela agroecologia, seria necessário tratar de várias questões tanto históricas quanto conceituais e politicas o que não nos permite nos limites deste artigo. Considerando que os estudos direcionados a decifra-lo são vastos e de fácil acesso, não nos deteremos sobre todos eles, mas buscaremos concentrar-nos nas determinações que nos possibilitarão compreender seu protagonismo na luta contra o agronegócio e o modelo agrícola convencional e a consolidação de uma proposta produtiva para o campo sustentada na defesa da agroecologia e da Soberania Alimentar.

Inicialmente pode-se afirmar que o MST, que já conta com 35 anos de existência, tem na sua trajetória e no seu protagonismo contemporâneo, elementos que nos permitem afirmar que é o movimento mais importante na história do país e com forte expressão na América Latina e em nível internacional. Suas táticas de luta expressas em ocupações de terras, acampamentos em beira de estradas, marchas, ocupações de prédios públicos, entre outras, garantelhe sua visibilidade do espaço público e lhe dão sustentação e organicidade. Hoje está organizado em quase todo território nacional, expressa uma ampla diversidade regional e política e mantem uma forte estrutura organizacional que lhe dá maior capacidade de resistência.

Nos primeiros anos, a atuação do movimento se volta à defesa da política da reformaagráriaalém deampliarsua inserção em outras regiões do país, para além da região sul, constituindo o que Fernandes (2000) denomina de territorialização do MST. Sua luta, juntamente com outras forças sociais existentes à época, a consolidação de uma série de assentamentos rurais e a aprovação de políticas e programas destinados à dinamização produtiva das áreas conquistadas tornando a organização produtiva uma demanda importante para o Movimento para garantir a viabilidade socioeconômica dos novos assentamentos rurais. $\mathrm{O}$ Movimento adota, a partir de então, a coletivização do trabalho o que culminou no projeto de cooperação agrícola tendo a cooperativa como a forma superior de organização do trabalho e da produção com uma conotação de cooperativismo produtivista aos moldes da Revolução Verde, a qual demandava a utilização em larga escala de insumos 
e tecnologias "modernas" tornando a produção dependente do crédito e do pacote tecnológico hegemônico.

Esse modelo mostrou-se pouco viável econômica-social e ambientalmente e enfrentou vários problemas, entre eles, questões com a organização da força de trabalho, a produção extremamente dependente de fatores externos, principalmente, os implementos agrícolas da indústria e o preço de venda da produção, regido internacionalmente (commodities). As cooperativas ficavam reféns da volatilidade do mercado para escoamento e comercialização da produção e não tardou para que demonstrasse a sua inviabilidade, somadoaindaa forterepressãoeperseguição do próprio governo ao Movimento e o corte de recursos para implementar esse modelo produtivo nos assentamentos (Borges, 2009), impulsionando, com isso, a reorientação produtiva abrindo espaço para a agroecologia.

As primeiras deliberações acerca deste tema aconteceram no III Congresso Nacional do MST, em 1995 que, de acordo com Grossi (2017), chega através do debate da questão ambiental levando a necessidade de necessidade de repensar a matriz produtivista nos assentamentos e defender a adoção de tecnologias adequadas ao processo de recuperação e preservação dos recursos naturais, condição para a garantia da segurança alimentar. Não é demais afirmar, também, que a partir de 1995 funda-se a Via Campesina, uma rede de cooperação internacional de organizações camponesas que tem como foco a luta contra a expansão do capitalismo na agricultura, expresso no domínio das grandes empresas transnacionais sustentadas no monopólio da produção e comércio de agrotóxico, transgênicos e máquinas. $\mathrm{O}$ MST como membro fundador desta rede e impulsionado por ela, assume a crítica ao agronegócio e passa a defender a matriz produtiva da agroecologia como estratégia para garantir a Soberania Alimentar.

Essa nova tendência se manifesta com mais profundidade no $4^{\underline{0}}$ Congresso
Nacional do MST, ocorrido em agosto de 200o, na cidade de Brasília. Nesse evento ganha mais força a denúncia ao agronegócio em ampla ascensão no Brasil, como visto no item anterior, e como contraponto definem-se as novas bases de luta política e das práticas produtivas, voltadas essencialmente para a agroecologia, a qual passou a ser o principal enfoque do projeto de transformação social almejado pelo Movimento. A reforma agrária continua como a principal bandeira do Movimento, mas a partir deste momento se incorpora a sustentabilidade o que significa intensificar os esforços na dimensão da produção, como demonstra Grossi (2017):

\section{Este congresso reafirmou a importância do debate em torno de questões importantes como: meio ambiente, biodiversidade, água doce, defesa da bacia de São Francisco e da Amazônia. Em seu documento final, realizou a denúncia das linhas políticas do governo adotadas para a agricultura e propôs a realização de ações concretas para a construção de um novo modelo tecnológico, sustentável do ponto de vista ambiental, com garanta de produtividade, viabilidade econômica e bem-estar social. (p. 25)}

A partir das deliberações deste Congresso e das articulações políticas com outras forças sociais voltadas a defesa da agroecologia esse tema se torna hegemônico e o setor responsável pela organização da produção no interior do Movimento incorpora a ideia de cooperação e meio ambiente o que o leva a realizar ações de grande envergadura contra as grandes empresas multinacionais, em parceria com a Via Campesina.

Os anos que se seguem a esse Congresso são de aprofundamento deste tema que vai culminar, em 2007, no $5^{\circ}$ Congresso Nacional do Movimento. Neste ganha expressão mais forte a luta contra o neoliberalismo e o imperialismo o que põe o agronegócio no centro das críticas. Por 
conseguinte, a agroecologia se firma como a alternativa mais viável e necessária para conter as investidas do grande capital e seu caráter predatório.

A palavra de ordem desse Congresso "Reforma agrária: por justiça social e soberania alimentar" indica os rumos do debate e demonstra que o MST segue os rumos já tomados por diversas organizações latino-americanas e, principalmente com a Via Campesina internacional, que já havia incorporado o tema da Soberania Alimentar desde a Conferência Mundial sobre Alimentação que ocorreu em Roma, em 1996. Esta era definida como o direito de cada nação de desenvolver sua capacidade de produzir alimentos, com respeito à diversidade cultural e natural de cada território. A ampliação deste conceito se deu posteriormente e se tornou a referência para o debate do MST que passa a indicar que os povos têm o direito de definir sua política agrícola (Vieira, 2018).

Ganha evidência, então, as mudanças nas orientações acerca do modelo produtivo o qual se contrapõe ao propagado anteriormente sob o domínio do modelo cooperativista na medida em que resgata e valoriza o saber tradicional camponês. A recuperação deste saber, que é a base da agroecologia, passa a ser valorizado de forma que sirva de referência para o avanço de novos conhecimentos científicos rumo a construção de um modelo de sustentabilidade e com garantia de equidade social, preservação ambiental e viabilidade econômica (Borges, 2009).

A qualificação técnica e política de seus quadros se tornou uma das maiores preocupações e, a partir de então, foram organizados vários cursos oferecidos através da parceria entre o Estado, algumas ONGs, Universidades e o Movimento. Vale mencionar o papel do Programa Nacional de Educação na Reforma Agrária (Pronera), uma política do governo federal que inicia no governo de Fernando Henrique Cardoso, mas que ganha espessura nos governos petistas o qual se propõe a ofertar cursos de espacialização e graduação e, entre eles estão vários voltados ao aprofundamento dos conhecimentos acerca da agroecologia. Mencionamos alguns aqui, os considerados mais importantes que são: Cursos de Residência Agrária; Curso de Agronomia para Movimentos Sociais no Campo; de Especialização em Agroecologia; Curso Técnico em Agropecuária com qualificação em Agroecologia e Meio Ambiente; etc. (Borges, 2009).

Considera-se um passo importante, também, no aprofundamento desse paradigma no interior do Movimento foi a criação da Escola Latino Americana de Agroecologia, no Assentamento Contestado na Lapa (Paraná). Em parceria com a Via Campesina e o governo do Paraná e da Venezuela e criada em 2005, se tornou uma das iniciativas mais importante para a inserção da Agroecologia no MST.

No que se refere especificamente as atividades realizadas por diversas instâncias do Movimento para fortalecer a agroecologia ganham forma através de diversasatividades etécnicas produtivas que vão sendo incorporadas pelo Movimento e paulatinamente implementadas em assentamentos rurais, tais como: sistema agroflorestal, instalação de viveiros agroflorestais comunitários, resgate de sementes crioulas, desenvolvimento de caldas naturais fungicidas e de biofertilizantes, etc.

Seguindo a linha do tempo e tendo em conta os Congressos realizados pelo MST e o tema da agroecologia é fundamental no referirmos ao último realizado em 2014 quando é elaborado a proposta de Reforma Agrária Popular. Pode-se afirmar que esse Congresso sintetiza os novos rumos do MST e segundo Bastos (2018), o que diferencia este Congresso com o realizado em 2007, é que este tinha como proposito resolver o problema da fome e o acesso à terra, enquanto que em 2014 a proposta era definir uma plataforma política e econômica ao Brasil. O argumento que se sobrepõe nesse Congresso era de que a reforma agrária nos moldes das revoluções burguesas clássicas já não teria como se efetivar no Brasil visto o 
crescimento e hegemonia do agronegócio. Portanto, esta deveria ser uma tarefa dos trabalhadores do campo, mas em parceria com os trabalhadores urbanos. O tema da alimentação se transforma no elo entre campo e cidade e, portanto, a produção de alimentos saudáveis através da matriz agroecológica ganha centralidade.

De acordo com esse autor:

O caminho escolhido para sensibilizar a população e a classe trabalhadora é a alimentação. A proposta sustentável do MST se traduz na produção de alimentos saudáveis, com matriz agroecológica, para a população brasileira, em contraposição ao agronegócio, cuja matriz tecnológica, política e econômica privilegia a produção em larga escala para a produção de commodities agrícolas. (Bastos, 2018 p. 226)

É certo afirmar, então, que nos últimos anos a alternativa de produção agroecológica tem se apresentado como a oposição ao modelo capitalista de produção materializado no agronegócio tornando-se o grande bastião do MST. A agroecologia surge como a força mais importante e ganha notoriedade junto ao Movimento o que leva a ampliação do diálogo com a sociedade diante do fortalecimento do debate acerca da alimentação saudável muito em voga nos anos mais recentes. Vale mencionar a realização de feiras agroecológicas em várias cidades do Brasil e a criação de lojas para comercialização dos produtos agroecológicos produzidos nos assentamentos que vem ganhando vários apoios e tem contribuído para diminuir a distância entre a população do campo e da cidade o que indica a veracidade do lema muito utilizado pela militância do MST que diz: se o campo não planta, a cidade não janta.

\section{Considerações finais}

A intenção deste artigo foi fazer uma breve recuperação de elementos acerca da constituição do modelo de produção agrícola no Brasil recuperando suas raízes e apontando as expressões contemporâneas que explicitam o caráter concentrador de riqueza e renda e altamente predatório ao meio ambiente e a saúde humana, materializado no que se convenciona chamar de agronegócio. Buscou-se recuperar as alternativas a esse modelo e, por isso chega-se à agroecologia e sua ainda curta trajetória no Brasil e a forma como está sendo incorporado pelo maior e mais importante movimento social que é o MST. Embora essa não tenha sido a matriz produtiva que orientou o Movimento desde de sua origem, atualmente vem sendo apresentada como a estratégia mais importante e com capacidade de resistir ao profundo retrocesso consolidado no campo brasileiro nos últimos anos.

Nesses tempos que grandes retrocessos que se apresenta hoje com a chegada ao poder de um presidente representante da ultradireita e os cortes no âmbito das políticas e programas governamentais o desmantelamento da estrutura institucional somada ao amplo processo de criminalização dos movimentos sociais, a terá grande impacto nos rumos da luta dos movimentos sociais e na consolidação de modelo agroecológico. Entretanto, a importância que a agroecologia vem tomando no contexto internacional e nacional nos permite afirmar que movimento não esmorecerá com essa ofensiva do capital, mas poderá se transformar em uma grande bandeira de resistência e de oposição ao modelo agrícola vigente, tendo cada dia mais capacidade e vitalidade para avançar na construção de uma sociedade mais justa e sustentável ambientalmente.

\section{Referências Bibliográficas}

Bastos, P. N. (2018). Desafios políticos e dialógicos ao projeto de reforma agrária popular do Movimento dos Trabalhadores Rurais Sem Terra. Revista Eptic, 20(1).

Bombardi, L. (2012). Intoxicação e morte 
por agrotóxicos no Brasil: a nova versão do capitalismo oligopolizado. http:// www.mst.org.br/sites/default/files

Borges, J. L. (2009). MST: do produtivismo a agroecologia. Anais do $1^{\circ}$ Seminário de Sociologia e Política. Curitiba: Universidade Federal do Paraná.

Carvalho, H. M. (2005). Transgênicos: semente do império. http://www. servicioskoinonia.org

Fernandes, B. M., Welch, C., \& Gonçalves, E. (2010). Agrofuel policies in Brazil: paradigmatic and territorial disputes. Journal of Peasant Studies, 37(4), p. 793-819.

Fernandes, F. (1987). A revolução burguesa no Brasil. Rio de Janeiro: Guanabara.

Goldfarb, Y. (2012). A agricultura a partir do neoliberalismo: financeirização, poder e as ameaças à soberania alimentar. Revista Agrária, (17).

Grossi, M. (2017). Questão ambiental, reforma agrária e agroecologia: desafios políticos ao MST. Revista Libertas, 17(2), 17-28. https://doi. org/10.34019/1980-8518.2017.v17.18525

Ianni, (1978). Escravidão e racismo. São Paulo: Editora HUCITEC.
Morais, C. (1997). Historia das Ligas Camponesas do Brasil. Brasilia: Ed. Iattermund.

MST. (2014). Carta do $5^{\circ}$ Congresso Nacional do MST. http://www.mst.org. $\mathrm{br} / 2009 / 06 / 22 / 5$-congresso-nacionaldo-mst.html

Nakatani, P., Faleiros, R. N., \& Vargas, N. C. (2012). Histórico e limites da reforma agrária na contemporaneidade brasileira. Serviço Social e Sociedade, 110, 213-240.

Nodari, R., \& Guerra, M. P. (2003). Plantas transgênicas e seus produtos: impactos, riscos e segurança alimentar (Biossegurança de plantas transgênicas). Revista de Nutrição, 1(16), p. 105-116.

Prado Júnior, C. (1961). Formação do brasil contemporâneo (colônia) (6th ed.). São Paulo: Editôra Brasiliense.

Teixeira, G. (2013). A Sustentação da Política e Economia do Agronegócio no Brasil. Revista da Associação Brasileira de Reforma Agrária.

Vieira, F. B. (2018). Via campesina: um projeto contra-hegemônico? http:// www.uel.br/grupo-pesquisa/gepal/ terceirosimposio/flaviabraga.pdf

\section{Sobre la Autora}

Maristela Dal Moto

Profesora Asociada de la Escuela de Servicio Social de la Universidad Federal de Río de Janeiro, Brasil. 